\title{
The Feasibility of Applying the Flipped English Classroom in Primary Schools in China
}

\author{
Xiaoning $\mathrm{Guo}^{1, \mathrm{a}}$ and Shu Zhu ${ }^{2, \mathrm{~b}}$ \\ Foreign Language School of Linyi University, China \\ aguoxiaoning@lyu.edu.cn, ${ }^{\mathrm{b}} 1340367579 @ q q . c o m$
}

Keywords: the flipped English classroom; primary schools; feasibility

\begin{abstract}
This paper analyzes the feasibility of implementing the flipped classroom in primary school English teaching. The flipped classroom can meet the physical and mental development of primary school students, increases classroom interaction, and improves the classroom management. At the same time, when the method of flipping is applied into practice, the following factors may challenge, such as lacking of technology support; teachers' misunderstanding of the flipped classroom and students' poor learning autonomy and so on. At last this paper comes up with solutions such as making full use of cyber source; providing teachers with training and lectures about the flipped classroom; asking students to make full use of the self-learning task list and providing some useful reference for pupils. It is hoped that this paper can provide some reference for the widely use of the flipped classroom in the primary school English teaching.
\end{abstract}

\section{Introduction}

As one of the most popular teaching methods in recent years, "the flipped classroom" has been raising much concern both at home and abroad. In short, this mode begins with students' independent study through short videos or other materials given by the teacher. And then, in the face-to-face class, it is unnecessary for teachers to present the new knowledge again, but to help students have more intensive understanding by making in-depth discussions [1]. Though the flipped classroom is considered as the most concerned in educational research, yet in China the research of the flipped classroom teaching mode is still in the exploration stage, the practice of the flipped classroom in China is not fully implemented, especially in primary schools. Therefore exploring the feasibility of using the flipped classroom teaching mode to improve the students' English proficiency in primary schools becomes the concern of the paper.

\section{Concept of the Flipped Classroom}

According to Maureen J. Lage and Gleen J. Platt, the flipped classroom is to transfer the teaching process which happened in traditional classroom to outside the classroom and vice versa [2]. The utilization of learning technology, especially the multi-media, provides students with new learning opportunities [3]. Intel global education director, Brian Gonzalez, calls the "flipped classroom" as the "inverted classroom", and deems that educators put the teaching process outside the classroom to let students choose the most suitable way to study the new knowledge; finishing the process of internalization of knowledge in the classroom to let students have more communication and exchange among students and teachers [4]. The key point of the flipped classroom is to offer students with exquisite and content-rich leaning materials in the form of mini-lectures or some short videos. According to students' learning conditions, students can be active to choose the time of watching videos under the guidance of teachers and parents. In this part, the biggest difference between the flipped classroom and the conventional one is the way that teachers adopt to impart knowledge to their pupils [5]. Therefore the flipped classroom in primary schools is sort of blended teaching model that needs primary students to study learning materials provided by teachers in advance; finish the learning task and share experience, discuss confusions and solve problems by cooperation with teachers and students. 
From the researchers' comprehend comprehension of the flipped classroom, the characteristics of the flipped classroom can be concluded as follows:

1. The flipped classroom is kind of "learning before teaching" mode.

2. The flipped classroom is a kind of "blended learning" mode.

3. The flipped classroom is suited to students with different learning styles.

4. The flipped classroom focuses on students' self-learning and cooperative abilities.

5. The flipped classroom needs abundant learning resources.

6.The flipped classroom advocates that teachers should evaluate students' study behavior on time.

\section{Advantages of the Flipped English Classroom in Primary Schools}

The flipped classroom reverses the traditional teaching form and structure, from original imparting knowledge in class and exercise after class to self-learning before class and exercise and exploration in class. Due to the structural reverse, the flipped classroom reveals its unique "magic".

Firstly, "flipping" helps students monitor their learning process. The flipping way provides students with elastic space: they can regulate the progress according to their abilities. They can arrange and decide their learning task according to their degree of internalization of new knowledge through the teaching videos. They can watch it repeatedly or press the pause button to ponder over the part they are unable to understand before class or in class. The flipped classroom meets the need of students' self-learning.

Secondly, "flipping" increases the frequency of interaction. The biggest benefit of the flipped classroom is to increase the class interaction between students and teachers and among students. The flipped classroom turns the role of teacher to the coach of study, which makes the teacher have more time and energy to converse with students, handle students' problems, participate in the study group and give specified guidance to every student.

Thirdly, the flipped classroom caters to the characteristics of primary students' growth of body and mind. Primary students are lively, lack of concentration and curious to novel stuff. The micro-video perfectly fits the students' features in this period.

Fourthly, "flipping" turns the teacher from a traditional imparter to a promoter and guider of learning. This means the teacher is not the center of knowledge interaction and application any more but the main promoter of student learning. Teachers will offer necessary support to students when they need the instruction. Hence, teachers become the scaffold when students acquire resources, make use of resources, process information, and apply knowledge to practical situation.

Fifthly, "flipping” leaves more time to activities. The flipped classroom shortens the imparting time and leaves more time to students for learning activities. Sufficient time and high efficiency are the key factors for students to finish the learning tasks through communication and cooperation. The flipped classroom maximizes the "preview time" to prolong the time of teaching and learning and gives teachers and students an opportunity of high efficiency of classroom.

Sixthly, the flipped classroom changes the management of primary class. Teachers need pay attention to students' behaviors all the time. In the flipped classroom, however, those mischievous students have no audience to watch their trick because every student is occupied in activity or cooperation. Every student has tasks to do in the flipped classroom.

\section{Challenges of the Flipped English Classroom in Primary Schools}

The flipped classroom is an exotic product in Chinese educational circle. It must be unadjusted to Chinese circumstance if the flipped classroom is completely migrated to Chinese class. Teachers need adjust the flipped approach according to the courses and students' characteristics to fit for local teaching. The flipped mode in primary English classroom meets some challenges from the operational perspective.

A. Challenges to schools

Firstly, the flipped classroom needs abundant finance and the support of information 
technology. Nowadays, most of the schools that have launched the flipped classroom all purchased panel computers, devices of video recording, routers, learning system software and so on. These equipments need much capital. Also no sufficient information technology support and lack of online learning platform make the application of flipped English classroom in the primary schools difficult. There are few of videos that can provide students with abundant and alternative teaching resources; the flipped classroom in primary school cannot be launched easily if there is no online platform.

Secondly, some schools ignore the subsequent investigation and assessment in teaching management. The schools cannot evaluate completely and objectively the effect and problems of implementing the flipping way because schools fail to investigate the attitudes and views of students, parents and teachers. Schools and teachers will have more enthusiasm in the flipped classroom if they know about students' positive attitudes toward flipping.

\section{B. Challenges to teachers}

Firstly, some teachers misunderstand the concept of the flipped classroom. There is little doubt that the flipped classroom is a blended learning approach. However, some teachers simply equate the flipped classroom with playing videos in classroom due to overstating the advancement of technology in practical learning. And some teachers think that the flipped classroom is assigning simple preview task before class together with traditional teaching in class. These teachers' comprehension of the flipping is one-sided and they ignore the essence of the flipped classroom. If things go on like this, the flipped classroom must be forgotten because of the limited functions.

Secondly, teachers need improve their abilities to have the flipped classroom. Teachers need have systematic and comprehensive awareness of the textbooks; have a clear view of every knowledge point in every chapter; arrange the learning content and form before class, in class and after class properly; know how to catch the key points to make video; design the guided learning plan scientifically and so on. Besides, teachers need properly arrange online pre-learning content and form to lighten students' learning burden, improve teaching efficiency and develop students' self-exploration and self-learning habits. Meanwhile, the guidance and monitoring of students' pre-learning and after learning need to be enhanced. Students study by watching the video before class and explore and extend the block knowledge after class which is based on students' self-learning and self-control abilities. Parents' monitoring time cannot be guaranteed and teachers cannot take effective ways to guide, help and monitor students' whole learning process.

C. Challenges to students

The flipped classroom requires students to have strong self-learning abilities. Before class, students finish the task list by watching the videos, and in class, students take part in discussion after independently speculation. However, students do not know what and how to learn because of some teachers' simple and uncertain tasks. What's worse, students only grope for in the dark due to lack of teachers' guidance.

The flipped classroom also requires students to have another important ability--cooperation. In class, students communicate and discuss with other classmates. Thus cooperation is the basement of the efficient learning. In some flipped classroom, students have no definite role in one group. Some students hold several posts simultaneously but others idle in the group.

\section{Suggestions}

The flipped classroom is an emerging teaching approach and its application into primary English is also an attempt and innovation. To solve the challenges mentioned above, some suggestions are offered here.

A. Improving conditions for the flipped English classroom implementation

Firstly, make full use of Internet resources. Teaching micro-videos are the important resources in the English flipped classroom. Mastering its manufacturing methods is the prerequisite and guarantee for the implement of the flipped classroom. Considering that the establishment of China's educational informatization is still in its infancy stage, some schools and families cannot support the needed equipment. To solve this problem, the East China Normal University and C20 MOOCs 
League established the "Huashi MOOCs" website. Teachers can make use of the website to handle with lack of online platform and teaching videos.

Secondly, build up school online learning platform. The flipped classroom in primary school cannot be launched easily if there is no online platform. It is difficult for individual to develop and operate the online platform let alone maintain and update it. However, schools can put the link of the micro-videos on the official website and set up a platform for exchange of students and teachers. Meanwhile, schools can use these popular softwares like QQ and Wechat to establish school online learning platform.

Thirdly, encourage teachers to design learning task list. In the early stage of the flipped classroom, the task list can make up for the lack of immediate analysis and feedback of students' learning behaviors and results. English learning task list in primary school consists of six parts: Learning Theme, Objectives, Methods and Suggestions, Foreshowing, Self-learning Task and Learning Confusions.

B. Improving teachers' abilities to apply the flipped English classroom

Firstly, strengthen theoretical study of the flipped classroom. Schools and bureau of education should arrange series of systematic training about the theories of the flipped classroom. The content of training should be composed of following theories: the origin of the flipped classroom, the definition and the practice at home and abroad of it, making teaching videos, functions of online platform and making self-learning task list.

Secondly, improve abilities of using information technology. Educational informatization is an inevitable trend of present educational reform. Under this trend, a qualified teacher should master the method of how to search, process and use information; choose the suitable teaching media according to teaching need and evaluate the using conditions scientifically.

Schools and bureau of education develop courses of educational information technology to organize teachers to study theory and practical cases according to local teachers' basic need and level. To improve the teachers' ability to use the information technology, they need not only the related knowledge but also the practice of the new technology.

C. Developing students' ability to attend the flipped English classroom

Firstly, develop students' self-learning ability. Self-learning requires students to take responsibility for their study and be able to actively study the learning materials without supervision and finish the task independently. Teachers should encourage the students to plan the schedule on their own. Students plan their own schedule and decide the learning process according to their learning level and comprehensible abilities. Also teachers should guide the learning approaches by helping students master the learning strategy. Students can develop their self-learning abilities by the following strategies (The English Curriculum Criteria, 2011, p.22).

a. Make simple English learning plan

(1) Review and summarize knowledge actively

(2) Establish the link between vocabulary and corresponding things

(3) Focus on in study

b. Try to read English stories and other after class books

(1) Take notice of easy English in life or media

(2) Study English by reference book

Besides, teachers should help students to use self-learning task list. Teachers design some self-learning task list corresponding with teaching content to ask students to finish it. Students will have a frame of the self-learning process after long-term usage of the task list and gradually form their own self-learning styles.

Secondly, develop students' cooperative ability. Cooperative learning is a kind of learning method that need students form into groups and help with each other and study together. The flipping mode requires students with high standard of cooperative ability.

a. Form into groups. At the early stage of forming groups, the conflict among members is inevitable. Therefore take following ways to form group identity and cohesion. 
(1) Discuss group names among group members

(2) Make group flag together

(3) Deliberate group catchword together

(4)Choose group motto

After establishing close relationship among members, every single member's role need be settled down. Students can be group leaders and members according their duties. Group leaders organize the group activities and group members carry out assigned task.

b. Take regular group activities. After forming the groups, members need take regular meet and activities. Sometimes, on the certain topic, they need share their gain and help with other members' confusions to achieve the learning goals.

c. Rethink cooperative process. Students need comment on group members' behaviors and give suggestion and feedback to others at the end of class or after finishing the tasks. The habit of introspection will help students increase the speed and improve the skill of short discussion task.

\section{Conclusion}

The flipped classroom, as the product of the combination of education with information technology, corresponds with educational wave in the future. This student-oriented teaching model does have strengths of improving teaching efficiency and satisfying every single student's personalized need to create a beneficial environment for students' active study.

However, the flipped classroom are still in its early stage in China and there must be some challenges in the process of application, especially in the primary schools, some factors that may challenge the successful application of the flipped classroom must be taken into consideration, such as lacking of technology support, teachers' misunderstanding of the flipped classroom and students' poor learning autonomy ability and so on. Therefore it is quite necessary to build up the online learning platform, provide teachers with training and lectures about the flipped classroom, ask students to make full use of the self-learning task list and provide some useful reference for primary pupils.

There is no denying that every novel teaching method has its own superiority and limitation and naturally cannot be fit for every discipline. In China, the application of the flipped classroom will not happen overnight because the implementation is still in the attempting stage. It is hoped that the experiment of the flipped classroom should be launched in more subjects and at more areas to collect enough effective information and provide more effective methods to promote the English teaching of primary schools.

\section{References}

[1] Bethany B. Stone. Flip Your Classroom to Increase Active Learning and Student Engagement. 28th Annual Conference on Distance Teaching \& Learning. 2012. http://www.uwex.edu/disted/conference/Resource_library/proceedings/56511_2012.Pdf

[2] Maureen J. Lage, Gleen J. Platt \& Michael Treglia. Inverting the classroom: A gateway to creating an inclusive learning environment [J]. The Journal of Economic Education, 2000, (31): 30-43.

[3] Tang Yu-lu. The Present Situation of Flipped English Classroom in Primary Schools - A Case Study of Primary School in Jinan City[D].Thesis for master's degree of Shandong Normal University.

[4] Yang Jiumin, Shao Mingjie, Huang Lei. The Application of Flipped Classroom Based on Micro-video Resources in Experimental Teaching:The Practice in Modern Educational Technology[J]. Modern Educational Technology, 2013, (10): 36-40.

[5] Zhong Xiaoliu, Song Shuqiang, Jiao Li-zhen. Instructional Design Based on the Idea of the Flipped Classroom in ICT Environment [J]. Open Education Research, 2013, (1): 58-64. 